\title{
Physiological Responses and Gene Expression in Ultrasound-Guided Supraclavicular Brachial Plexus Block: a Comparative Study
}

\author{
Hayam G. Sayyed Naglaa K. Idriss $^{\mathrm{b}} \quad$ Marwa A. Gaber $^{\mathrm{b}} \quad$ Sherif Sayed $^{\mathrm{c}}$ \\ Rasha Ahmedc \\ Departments of a Medical Physiology, ${ }^{\mathrm{b}}$ Medical Biochemistry and ${ }^{\mathrm{C} A n e s t h e s i o l o g y, ~ F a c u l t y ~ o f ~ M e d i c i n e, ~}$ \\ Assiut University, Assiut, Egypt
}

\section{Key Words}

Ultrasound-guided supraclavicular brachial plexus block $•$ Midazolam $•$ Neostigmine

\begin{abstract}
Background/Aims: Ultrasound-guided supraclavicular brachial plexus block (BPB) has come into wider use as a regional anesthetic during upper limb operations. This study assessed the neurological and hemodynamic changes and gene expression after co-administration of midazolam or neostigmine with bupivacaine during supraclavicular BPB. Methods: The study involved 90 adults divided into three groups: control (bupivacaine), midazolam (bupivacaine plus midazolam), and neostigmine (bupivacaine plus neostigmine). Blood samples were taken and interleukin-6 (IL-6) and tumor necrosis factor-alpha (TNF- $\alpha$ ) mRNA levels were measured by real-time PCR, and oxidative stress markers were identified. In addition to the hemodynamic variables, the onset and duration of sensory and motor blockades, duration of analgesia, pain scores, time of first request for an analgesic, and amounts of analgesics ingested were evaluated. Results: Compared with the control and neostigmine groups, the midazolam group experienced longer sensory and motor blockades, prolonged analgesia, lower pain scores at $12 \mathrm{~h}$ and $24 \mathrm{~h}$, and lower need for postoperative analgesics. Moreover, the midazolam group exhibited lower oxidative stress markers with a higher fold change in IL- 6 and TNF- $\alpha$ mRNA levels. Conclusion: Midazolam co-administered with bupivacaine provided better analgesic quality than did neostigmine with bupivacaine. This might be due to its superior antioxidant and anti-inflammatory effects.
\end{abstract}

(C) 2018 The Author(s)

Published by S. Karger AG, Basel

\section{Introduction}

Supraclavicular brachial plexus block (BPB) is an excellent substitute for general anesthesia during upper limb operations. It prevents the undesirable effects of using

Hayam G Sayyed

KARGER
Medical Physiology Department, Faculty of Medicine,

Assiut University, Assiut, (Egypt)

Tel. +201011826773, Fax +20882332278, E-Mail hayam_said3@aun.edu.eg 
general anesthesia and upper airway instruments [1]. Moreover, it reduces the duration of hospitalization and costs, and provides complete muscle relaxation [1,2]. The ultrasoundguided technique requires a lower anesthetic volume to provide an efficient block and decreases the risk associated with intravascular injections and trauma to the surrounding tissues [3].

Bupivacaine alone is now less frequently used as a local anesthetic because of its short duration of action [3]. Several adjuvants have been co-administered with bupivacaine, but the results have been either unconvincing or associated with untoward complications [4]. Several researchers have attempted to combine bupivacaine with other anesthetics such as ketamine [5], clonidine [6], midazolam [1], and neostigmine [7] with various success rates.

Midazolam, a water-soluble benzodiazepine, reduces pain perception [1] via postsynaptic gamma-aminobutyric acid $\left(\mathrm{GABA}_{A}\right)$ receptors, opioid receptors, and benzodiazepine receptors in the spinal cord. GABA $\mathrm{A}$ receptor is a chloride ionophore that, when activated, decreases neural excitability by stabilizing the membrane potential near the resting potential [8]. Kohno et al. [9] have demonstrated the presence of GABA receptors within the brachial plexus and peripheral nerve trunks. Yamamoto et al. [10] have reported that these receptors enhance membrane translocation of alpha-7 nicotinic subtype acetylcholine receptors at presynaptic GABAergic neurons to allow endogenous acetylcholine to increase the release of presynaptic GABA within the rat neocortex.

Neostigmine, a reversible acetylcholinesterase inhibitor, prevents the breakdown of acetylcholine [7]. Lin et al. [11] reported that it enhances the release of nitric oxide, suppresses the expression of Fos, and activates muscarinic M2 receptors within the spinal cord.

This study aimed to estimate the neurological and hemodynamic changes and the antioxidant plus anti-inflammatory effects associated with adding either midazolam or neostigmine to bupivacaine during supraclavicular BPB.

\section{Materials and Methods}

\section{Subjects}

Inclusion criteria were unilateral upper limb operation except on the shoulder, age 18-70 years, weight $59-95 \mathrm{~kg}$, and American Society of Anesthesiologist physical status I or II. Exclusion criteria were patient refusal; allergy to the drugs used; contraindications for regional block; use of drugs that may modify pain perception; upper limb peripheral neuropathy; cardiac, respiratory, hepatic, or renal disease; infection; incomplete block; and pregnancy. The protocol of this study was supported by the ethics committee of our institution. Written, informed consent was obtained from all patients.

This was a prospective double-blind study; neither the patients nor operators were informed of which drugs were used in each case. Another anesthetist was responsible for allocating the patients to the study groups and loading the drugs for each block. A total of 90 patients took part in the study (30 patients in each group). Patients were allocated randomly by the computer-generated block method into the following groups.

1. Control group: Ultrasound-guided supraclavicular BPB with $30 \mathrm{~mL} 0.5 \%$ bupivacaine.

2. Midazolam group: Ultrasound-guided supraclavicular BPB with $28 \mathrm{~mL}$ bupivacaine $0.5 \%$ plus 2 $\mathrm{mL}$ midazolam $(50 \mu \mathrm{g} / \mathrm{kg}$ body weight).

3. Neostigmine group: Ultrasound-guided supraclavicular BPB with $28 \mathrm{~mL}$ bupivacaine $0.5 \%$ plus 2 mL neostigmine $(200 \mu \mathrm{g})$.

\section{Supraclavicular block}

After aseptic preparation of the area, the supraclavicular block was performed by the anesthetist using SonoAce 6 ultrasound machine with a high-frequency linear probe. The patient head was slightly raised and rotated opposite to the surgery site. Anesthetist stood at the patient's head with ultrasound machine. A superficial linear probe put in supraclavicular fossa, the supraclavicular artery was identified 


\section{Cellular Physiology Cell Physiol Biochem 2018;46:2412-2420 \\ \begin{tabular}{l|l} 
and Biochemistry Published online: May 09, 2018 & $\begin{array}{l}\text { Do } 2018 \text { The Author(s). Published by S. Karger AG, Basel } \\
\text { www.karger.com/cpb }\end{array}$ \\
\hline SOl.1159/00489647
\end{tabular}}

Sayyed et al.: Physiological and Biochemical Changes in Supraclavicular BPB

as a hypoechoic pulsating structure above first rib which visualized as hyperechoic line. The plexus usually appeared as a set of hypoechoic rounded structures (grapes bunch) reclined superior and dorso-lateral to subclavian artery.

\section{Hemodynamic variables}

Heart rate (HR) and mean arterial blood pressure (MABP) measurements were recorded preoperatively (baseline level), intra-operatively (these variables were recorded at $5 \mathrm{~min}, 10 \mathrm{~min}, 15 \mathrm{~min}, 30$ $\mathrm{min}, 60 \mathrm{~min}$, and at the end of surgery), and again postoperatively at $30 \mathrm{~min}$ and $60 \mathrm{~min}$.

\section{Neurological assessment}

The following parameters were monitored:

Sensory block onset is defined as the time taken between administration of the anesthetic $\operatorname{drug}(\mathrm{s})$ and complete block. Sensory block was monitored by pinprick from C4 to T1 dermatomes and scored as follows: $0=$ normal sensation and $1=$ loss of tactile sensation (anesthesia).

Motor block onset is defined as the time taken between the administration of the anesthetic $\operatorname{drug}(\mathrm{s})$ and total muscle power loss. Motor block score: 0 = normal motor function with full flexion and extension of elbow, wrist, and fingers; 1 = decreased muscle strength but able to move the fingers only; and 2 = total motor block with an inability to move the fingers.

Sensory block duration is the time taken between the beginning of total sensory block and the appearance of pain.

Motor block duration is the time from total motor block to the return of full muscle power.

Analgesia duration is the time taken between successful block and the subject sensing pain that requires an analgesic.

First analgesic request is how long it takes the patient to ask for the first postoperative analgesic.

Pain management was assessed by evaluating pain on a visual analog scale (VAS) where zero represents no pain and 10 the worst possible pain. Significant pain is described as a pain level score of 4 requiring analgesia ( $15 \mathrm{mg} / \mathrm{kg}$ of paracetamol every $6 \mathrm{~h}$ ). In cases of VAS $\geq 6$ an additional analgesic was given in the form of $1 \times 25-\mu \mathrm{g}$ fentanyl transdermal patch/h. VAS was measured at $0 \mathrm{~min}, 30 \mathrm{~min}, 60 \mathrm{~min}, 2 \mathrm{~h}, 4 \mathrm{~h}, 12 \mathrm{~h}$, and $24 \mathrm{~h}$ postoperatively.

\section{Laboratory}

Samples $(3 \mathrm{~mL})$ of blood were saved in heparinized tubes immediately before the analgesics were administered (baseline), and at $2 \mathrm{~h}, 4 \mathrm{~h}$, and $24 \mathrm{~h}$ thereafter. Blood was immediately centrifuged at $4{ }^{\circ} \mathrm{C}$ at $3,000 \times \mathrm{g}$ for $10 \mathrm{~min}$, divided into aliquots, and stored at $-80^{\circ} \mathrm{C}$ until the enzyme-linked immunosorbent assays for the measurement of 8-Epi-prostaglandin F2 alpha (8-Epi-PGF ${ }_{2 \alpha}$ ) and superoxide dismutase (SOD) according to the instructions supplied with each kit. Lipid peroxidation product malondialdehyde (MDA) was measured using spectrophotometry [12]. Quantitative real time-polymerase chain reaction (qRT-PCR) was utilized to estimate interleukin-6 (IL-6) and tumor necrosis factor-alpha (TNF- $\alpha$ ) mRNA levels, as described below in the RNA extraction subsection. All PCR reagents were from Applied Biosystems (Foster City, CA, USA). Subsequently, the cDNA was amplified with the SYBR Green I PCR Master Kit (Fermentas) using the Step One instrument and examined using $\mathrm{RT}^{2} \mathrm{SYBR} \circledast$ (Precision PLUS Master Mix premixed with SYBR green). Extracted RNA was transformed to cDNA. Primer Express software was used for PCR amplification. Each reaction had 50 cycles and was performed in triplicate, s as per the manufacturer's recommendation.

RNA extraction

RNA extraction was achieved with Rnase extraction kit (according to manufacturer's directions). The Ct values of of four genes relative to the concentrations of housekeeping gene RNAs were calculated. Briefly, RNA expression was determined using Precision PLUS Master Mix premixed with SYBR green, and $12.8 \mathrm{~mL}$ $(8 \times 1.6 \mathrm{~mL})$ samples were prepared for reverse transcription using the Precision NanoScript 2 Reverse Transcription kit.

Reverse transcription

One-microgram samples of total RNA were reverse transcribed using the Applied Biosystems Taqman RT-Kit. IL-6 and TNF- $\alpha$ gene expression levels were assessed with qRT-PCR. The primer 
sequences used were: IL-6, forward primer (5-`GGTACATCCTCGACGGCATCT-3`) and reverse primer (5`-GTGCCTCTTTGCTGCTTTCAC-3`); TNF- $\alpha$, forward primer (5'-GCG ACG TGG AAC TGG CAG AAG-3') and reverse primer (5'-GGT ACA ACC CAT CGG CTG GCA-3') [14]. Each sample was run in triplicate in a reaction volume of $20 \mathrm{~mL}$ for 50 cycles using standard RT-PCR cycling conditions. All samples were normalized to a relative standard curve and the amounts of gene transcripts were normalized to the housekeeping genes. The reactions were performed by a thermal cycler (MJ Research, Inc., MA, USA). The amplification conditions were: 30 cycles of template denaturation at $94{ }^{\circ} \mathrm{C}$ for $1 \mathrm{~min}$, annealing at $55^{\circ} \mathrm{C}$ for $1 \mathrm{~min}$, then polymerization at $72{ }^{\circ} \mathrm{C}$ for $2 \mathrm{~min}$. However, annealing for TNF- $\alpha$ was performed at $58{ }^{\circ} \mathrm{C}$ for $90 \mathrm{~s}$ and extension was at $72{ }^{\circ} \mathrm{C}$ for 140 s. All data were normalized by the mean critical threshold $(\mathrm{Ct})$ values of the GAPDH housekeeping gene [13], and are reported as fold changes in expression [forward primer (5'-TCG TGG AAG GAC TCATGA C-3') and reverse primer (5'-CCA TCA CGC CAC AGT TT-3')].

\section{Statistics}

Data were analyzed by the Statistical Package for the Social Sciences, version 21 (SPSS, Chicago, Illinois, USA). Data are presented as the mean \pm standard deviation (SD) or number. The Shapiro-Wilk test was used to detect normal distribution. Categorical data were examined by the Chisquared test. Continuous variables were examined by analysis of variance or the Kruskal-Wallis test. Data at multiple time points were analyzed by repeated measures analysis of variance with Tukey's post-hoc test. Differences between the groups were regarded as statistically significant when the $P$ value was less than 0.05 .

\section{Results}

Table 1 presents the demographic data and characteristics of the participants. No significant intergroup differences were found among the patients' characteristics.

Fig. 1 shows the motor and sensory blockades onset times. Compared with the
Table 1. Demographic and clinical characteristics of the groups studied. Values are presented as the mean \pm standard deviation or number and were analyzed by one way analysis of variance followed by Bonferroni or chi-squared tests. ASA, American Society of Anesthesiologists; BMI, body mass index

\begin{tabular}{|c|c|c|c|}
\hline & Control group & Midazolam group & Neostigmine group \\
\hline & $(n=30)$ & $(n=30)$ & $(\mathrm{n}=30)$ \\
\hline Age (years) & 33.1 (11) & $37.1(10.6)$ & $33.1(9)$ \\
\hline Men/women & $26 / 4$ & $27 / 3$ & $24 / 6$ \\
\hline Height $(\mathrm{cm})$ & $175.9(5.2)$ & $174(7.5)$ & $178.5(6.8)$ \\
\hline Weight (kg) & $55.9(6.1)$ & $51.3(5.8)$ & $53.1(5.2)$ \\
\hline BMI $\left(\mathrm{kg} / \mathrm{m}^{2}\right)$ & $18.1(2.4)$ & $17.1(2.7)$ & $17.1(1.9)$ \\
\hline Duration of surgery (min) & $103.3(17.4)$ & $106.8(21.5)$ & $104.6(23.2)$ \\
\hline \multicolumn{4}{|l|}{ Type of surgery } \\
\hline Bone/soft tissue & $18 / 12$ & $14 / 16$ & $20 / 10$ \\
\hline \multicolumn{4}{|l|}{ ASA grade } \\
\hline I/II & $24 / 6$ & $26 / 4$ & $28 / 2$ \\
\hline
\end{tabular}

Fig. 1. Onset times of motor and sensory blockades. Data are presented as the mean \pm standard deviation, $\mathrm{n}$ $=30$ subjects per group. KruskalWallis test was

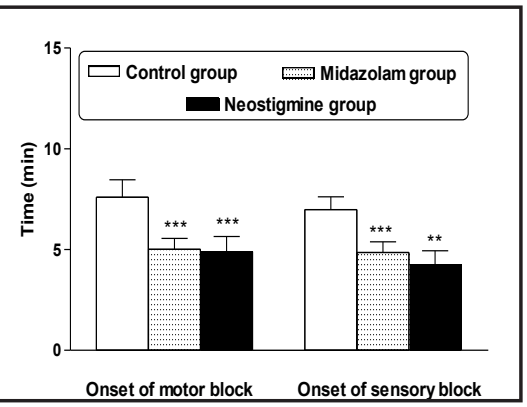
used to examine the data. ${ }^{* *} \mathrm{P}<0.01$ and ${ }^{* * *} \mathrm{P}<0.001$, significantly different compared with the control group.

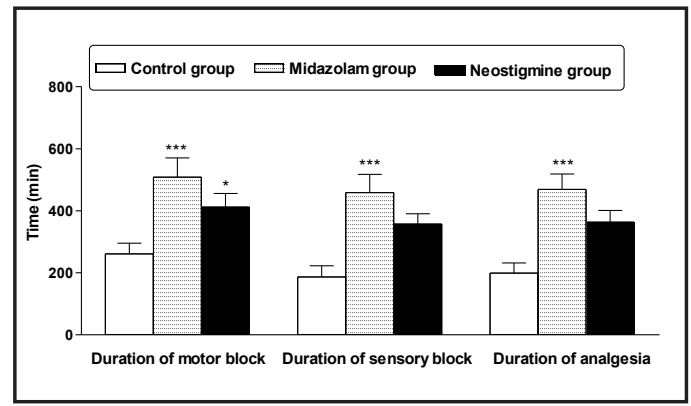

Fig. 2. Durations of motor and sensory blockades and analgesia. Data are presented as the mean \pm standard deviation; $\mathrm{n}=30$ subjects per group. Kruskal-Wallis test was used to examine the data. ${ }^{*} \mathrm{P}<0.05$ and $* * * \mathrm{P}<0.001$, significantly different compared with the control group. 
control group, the midazolam and neostigmine groups had significantly faster onsets of motor block $(7.60 \pm 0.87$ $\min$ vs. $5.02 \pm 0.53 \mathrm{~min}, P<$ 0.001 , and $4.90 \pm 0.75 \mathrm{~min}$, $P<0.001$, respectively) and sensory block $(6.99 \pm 0.63$ $\min$ vs. $4.86 \pm 0.53 \mathrm{~min}, P<$ 0.001 , and $4.38 \pm 0.69 \mathrm{~min}$, $P<0.001$, respectively). There was no difference between the midazolam and neostigmine groups.

The durations of motor block, sensory block, and analgesia are shown in Fig. 2 . Compared with the control group, the midazolam and neostigmine groups showed significantly longer durations of motor block $(261.10 \pm 34.66 \mathrm{~min}$ vs. $508.50 \pm 62.09 \mathrm{~min}, P<0.001$, and $412.00 \pm 43.72 \mathrm{~min}$, $P<0.05$, respectively) but only the midazolam group experienced longer sensory blocks $(186.50 \pm 36.31 \mathrm{~min}$ versus $458.50 \pm 58.87 \mathrm{~min}, P$ $<0.001$ ). Similarly, analgesia was significantly longer in the midazolam group compared with the control group (469.00 \pm 49.30 min vs. $199.00 \pm 32.91$ min, $P<0.001)$; however, there was no difference between the midazolam and neostigmine groups.

Fig. 3 shows the VAS pain scores at different time points. The highest and most significant VAS pain scores in the control group were found at 2 $\mathrm{h}, 4 \mathrm{~h}, 12 \mathrm{~h}$, and $24 \mathrm{~h}$ postoperatively, while the midazolam group had lower VAS scores than did the neostigmine group $(P<0.05$ at $12 \mathrm{~h}$ and $24 \mathrm{~h}$ postoperatively).

The first requests for an analgesic were significantly later in the midazolam and neostigmine groups than in the control group $(9.56 \pm 2.24 \mathrm{~h}, P<0.001$ and $7.65 \pm 1.53 \mathrm{~h}, P<$ 0.05 versus $6.05 \pm 1.17 \mathrm{~h}$, respectively; Fig. 4). The amount of paracetamol consumed in the $24 \mathrm{~h}$ following surgery was significantly lower in the midazolam group than in the control and neostigmine groups $(1.96 \pm 0.35 \mathrm{~g}$ vs. 2.91 $\pm 0.34 \mathrm{~g}, P<0.001$, and $2.49 \pm 0.64 \mathrm{~g}, P<0.01$, respectively).

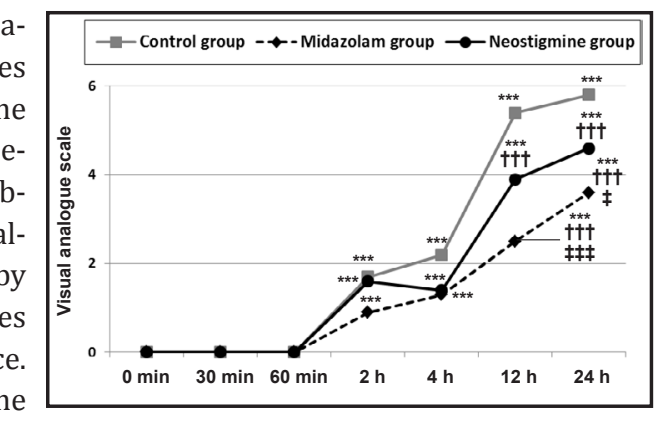

baseline level of every

group were examined by Mann-Whitney test. ${ }^{* * *} \mathrm{P}<0.001$, significantly different from baseline; $\uparrow \dagger \dagger \mathrm{P}<0.001$, significantly different from the control group; and $\neq \mathrm{P}<0.05$ and $\neq \neq \neq \mathrm{P}<0.001$, significantly different from the neostigmine group.

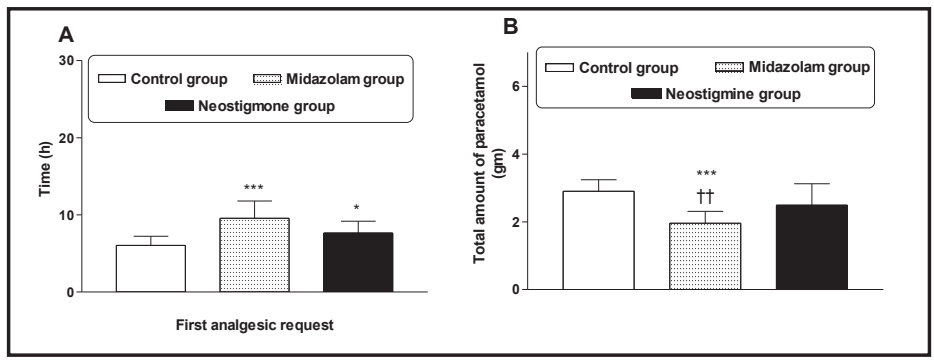

Fig. 4. Time of the first request for an analgesic (A) and total amount of paracetamol (B). Data are presented as the mean \pm standard deviation, $\mathrm{n}=30$ subjects in every group. Kruskal-Wallis test was performed to examine the data. ${ }^{*} \mathrm{P}<0.05$ and ${ }^{* * *} \mathrm{P}<0.001$, significantly different from the control group; and $\uparrow \dagger \mathrm{P}<0.01$, significantly different from the neostigmine group.

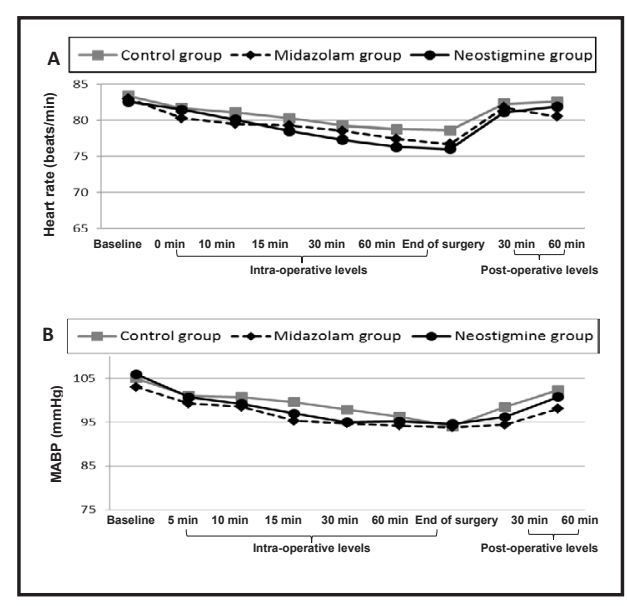

Fig. 5. Heart rates (A) and MABPs (B) of the participants. Data are presented as the mean \pm standard deviation, $\mathrm{n}=30$ subjects per group. Data were examined by repeated measures analysis of variance. MABP, mean arterial blood pressure. 
Fig. 5 shows the hemodynamic parameters. There were no significant intergroup differences of HR and MABP levels.

Fig. 6 shows the plasma 8-Epi-PGF ${ }_{2 \alpha}$,MDA and SOD concentrations. The concentrations of 8-Epi$\mathrm{PGF}_{2 \alpha^{\prime}}$ MDA, and SOD were not statistically different at either baseline or $24 \mathrm{~h}$ following anesthetic drug injection among the study groups. However, at $2 \mathrm{~h}$ and $4 \mathrm{~h}$, the plasma 8-Epi$\mathrm{PGF}_{2 \alpha}$ concentrations increased significantly in all groups compared with the baseline concentrations (P $<0.001$ for each group), with significant elevations in the control group compared with the midazolam and neostigmine groups $(272.40 \pm 28.46 \mathrm{pg} / \mathrm{mL}$ vs $221.50 \pm 14.74 \mathrm{pg} / \mathrm{mL}, \mathrm{P}<$ 0.001 , and $247.10 \pm 22.33$ $\mathrm{pg} / \mathrm{mL}, \mathrm{P}<0.05$, respectively) and (386.60 \pm 26.06 $\mathrm{pg} / \mathrm{mL}$ vs. $336.70 \pm 42.51$ $\mathrm{pg} / \mathrm{mL}, \quad \mathrm{P}<0.001$, and $361.90 \pm 32.62 \mathrm{pg} / \mathrm{mL}, \mathrm{P}<$ 0.05 , respectively), with a more significant decline in the midazolam group than in the neostigmine group $(P<0.05$ at every time point).

Similarly, at $2 \mathrm{~h}$, the MDA concentrations increased significantly in the control and neostigmine

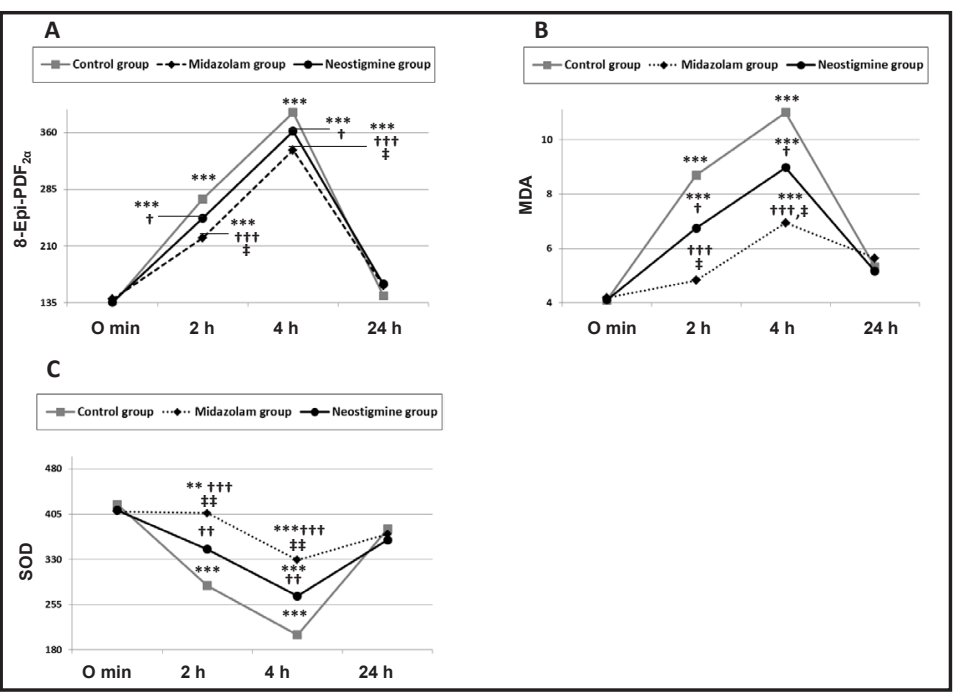

Fig. 6. Plasma concentrations of (A) 8-Epi-PGF2 $\alpha$, (B) MDA, and (C) SOD among the groups. Data are presented as the mean \pm standard deviation, $\mathrm{n}=30$ subjects per group. Data were examined by repeated measures analysis of variance. Differences from baseline in each group were examined by Mann-Whitney test. ${ }^{* * *} \mathrm{P}<0.001$, significantly different from the baseline level. $\dagger \mathrm{P}<0.05$, $\dagger \dagger \mathrm{P}<0.01$, and $+\dagger \dagger \mathrm{P}<0.001$, significantly different from the control group; $\neq \mathrm{P}<0.05$ and $\neq \neq \mathrm{P}<0.01$, significantly different from the neostigmine group. 8-Epi-PGF2 $\alpha$, 8-Epi-prostaglandin F2 alpha; MDA, malondialdehyde; and SOD, superoxide dismutase.

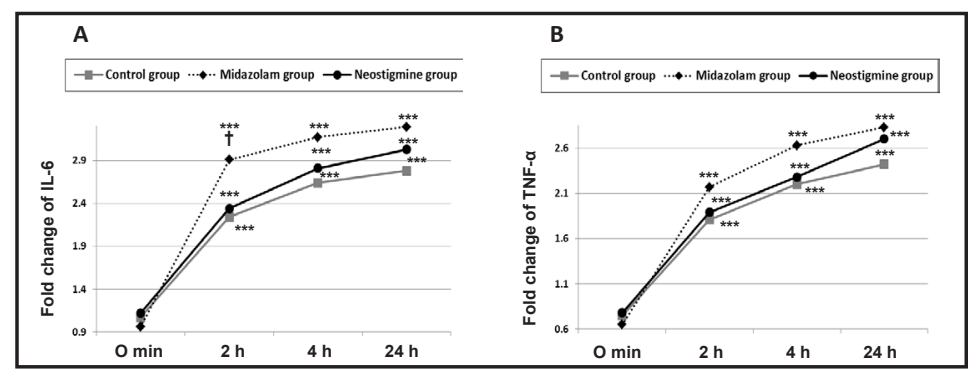

Fig. 7. Real-time PCR products of (A) IL-6 and (B) TNF-alpha in Ct values relative to housekeeping gene RNAs. Data are presented as the mean \pm standard deviation, $\mathrm{n}=30$ subjects per group. Data were examined by repeated measures analysis of variance. Differences from baseline in each group were examined by Mann-Whitney test. ${ }^{* * *} \mathrm{P}<0.001$, significantly different from baseline level. $\uparrow \mathrm{P}<0.05$, significantly different from the control group. IL-6, interleukin-6; TNF- $\alpha$, tumor necrosis factor-alpha. groups compared with the baseline concentrations $(\mathrm{P}<0.001$ for each). At $4 \mathrm{~h}$, plasma MDA concentrations increased significantly in each of the three groups $(\mathrm{P}<0.001$ for each). Compared with that in the control group, the concentration of MDA diminished significantly in the midazolam and neostigmine groups $(8.69 \pm 1.20 \mathrm{nmol} / \mathrm{L}$ vs. $4.83 \pm 0.98 \mathrm{nmol} / \mathrm{L}, \mathrm{P}<0.001$, and $6.75 \pm 0.82 \mathrm{nmol} / \mathrm{L}$, $\mathrm{P}<0.05$, respectively), and $(11.01 \pm 1.70 \mathrm{nmol} / \mathrm{L}$ vs. $6.94 \pm 0.83 \mathrm{nmol} / \mathrm{L}, \mathrm{P}<0.001$, and 8.98 $\pm 1.51 \mathrm{nmol} / \mathrm{L}, \mathrm{P}<0.05$, respectively), with a more significant reduction in the midazolam group than in the neostigmine group $(P<0.05$ at every time point).

In contrast, at $2 \mathrm{~h}$ and $4 \mathrm{~h}$, the plasma SOD concentration declined significantly in the control ( $\mathrm{P}<0.001$ in each time point) and neostigmine $(\mathrm{P}<0.01$ and $\mathrm{P}<0.001$, respectively) groups compared with the baseline concentrations, while they were no different from the 
baseline concentration at $2 \mathrm{~h}$ and had decreased significantly at $4 \mathrm{~h}(\mathrm{P}<0.001)$ in the midazolam group. Compared with the control group, the reduction in SOD concentration was less significant in the midazolam and neostigmine groups (286.50 $\pm 35.65 \mathrm{U} / \mathrm{L}$ vs. $406.60 \pm$ $19.03 \mathrm{U} / \mathrm{L}, \mathrm{P}<0.001$, and $346.80 \pm 42.59 \mathrm{U} / \mathrm{L}, \mathrm{P}<0.01$, respectively) and (204.80 \pm 26.06 $\mathrm{U} / \mathrm{L}$ vs. $329.00 \pm 32.64 \mathrm{U} / \mathrm{L}, P<0.001$, and $269.00 \pm 44.83 \mathrm{U} / \mathrm{L}, \mathrm{P}<0.01$, respectively), with a significant decline in the midazolam group compared with the neostigmine group $(P<0.01$ at every time point).

Fig. 7 demonstrates the IL- 6 and TNF- $\alpha$ RT-PCR Ct values relative to housekeeping gene RNAs. IL- 6 and TNF- $\alpha$ gene concentrations rose significantly compared with baseline concentrations $(P<0.001$ for every parameter at each time point $)$ in the three groups but there was no difference among the groups at $0 \mathrm{~h}, 4 \mathrm{~h}$, and $24 \mathrm{~h}$ following the administration of the anesthetic drugs. At $2 \mathrm{~h}$, the fold change in IL- 6 was higher in the midazolam group ( $P$ $<0.05$ for every parameter) compared with the control group.

\section{Discussion}

Many additives are used to improve the quality of analgesics, but the results are either uncertain or associated with undesirable adverse effects [1]. This study revealed that the addition of midazolam to bupivacaine during ultrasound-guided supraclavicular BPB provided better neurological and analgesic qualities than the addition of neostigmine. These effects might be attributable to the greater anti-oxidant and anti-inflammatory effects of midazolam.

Analgesic quality is improved by a quick onset time plus prolonged sensory and motor blockades [14] . The present study concurred with the data of Kamali et al. [15] who found more prolonged sensory blockade in their midazolam- group than in the control group. In contrast, Kumar et al. [16] found that neostigmine provided more prolonged sensory and motor blockades and a longer period of analgesia than midazolam.

Postoperative pain, a physiological reaction to tissue injury, can result in unpleasant physiological and metabolic effects as well as adverse emotional experiences if it is inadequately managed $[15,17]$. The following study revealed that the addition of midazolam to bupivacaine resulted in a greater reduction in postoperative pain and the need for fewer analgesics than did the addition of neostigmine. Similarly, Kamali et al. [15] found that coadministration of midazolam and lidocaine during spinal anesthesia decreased the severity of postoperative pain and postoperative analgesic consumption to a greater degree than co-administration of neostigmine and lidocaine. In contrast, Kumar et al. revealed that the time points of the first postoperative analgesics were not considerably different between the bupivacaine-neostigmine and bupivacaine-midazolam groups [16].

This study showed that the addition of either midazolam or neostigmine to bupivacaine provoked no intra- or postoperative changes in HR or MABP. These results agree with previous studies that have reported stable HR and MABP measurements throughout the surgical procedure when bupivacaine is co-administered with either midazolam [14] or neostigmine [16] .

Surgical stress can decrease antioxidant activities in the body and oxidative stress can lead to elevations in the levels of free radicals [18]. Thus, the use of an anesthetic drug with antioxidant effects to lessen oxidative stress is crucial and of significant clinical value [19]. Lipid peroxidation, the principal mechanism of cell damage mediated via free radicals, can reduce membrane fluidity along with permeability and cause denaturation of cell membrane proteins [20]. The arachidonic acid peroxidation product 8-epi-PGF ${ }_{2 \alpha}$ is an often used as an oxidative stress marker [21]. MDA is a lipid peroxidation product often used as an oxidative stress indicator. SOD is the main free radical scavenger concerned with the elimination of superoxide anion [17]. This study revealed that co-administration of midazolam with bupivacaine exhibited a more potent antioxidant effect than the co-administration of neostigmine with bupivacaine by decreasing the plasma levels of 8-Epi-PGF ${ }_{2 \alpha}$ and MDA and 


\section{Cellular Physiology Cell Physiol Biochem 2018;46:2412-2420 \begin{tabular}{l|l} 
and Biochemistry Published online: May 09, 2018 & $\begin{array}{l}\text { D) } 2018 \text { The Author(s). Published by S. Karger AG, Basel } \\
\text { www.karger.com/cpb }\end{array}$
\end{tabular}}

Sayyed et al.: Physiological and Biochemical Changes in Supraclavicular BPB

enhancing those of SOD. In line with the present study, Kang et al. reported that midazolam exerts antioxidant activity whereas neostigmine has no such effect [19]. In contrast, Bondok et al. demonstrated in an experimental acute liver failure model that neostigmine could have a protective effect by reducing MDA and increasing SOD levels in the liver [22]. This suggests that postoperative pain may in part result from oxidative stress. Kim et al. reported that antioxidants reduce the hyperalgesia of neuropathic pain. In addition [23], Eisenberg et al. showed that salivary and serum antioxidants, in addition to serum MDA concentrations, are raised in subjects with complex regional pain syndrome and spinal neurons are sensitized [24].

It has been implied that anesthesia might reduce inflammatory responses by repressing the release of cytokines [25]. The present study revealed that the co-administration of midazolam and bupivacaine reduced inflammation, which was identified by higher fold changes in the expression of IL-6 mRNA. In contrast, Bondok et al. [22] reported that neostigmine reduces the expression of TNF- $\alpha$ and increases the expression of IL-10 in rat liver. Unfortunately, the results of this study cannot be compared with those of Bondok et al. [22] because in that study, neostigmine was the only drug investigated. Our results suggested that midazolam may reduce inflammatory responses; however, further studies are needed.

Several studies have suggested that proinflammatory cytokines facilitate the development and continuation of persistent pain syndrome. TNF- $\alpha$ has been proposed to play a substantial role in the pathogenesis of pain [26, 27]. Furthermore, IL-6 provokes muscle and joint hyperalgesia [28] and the development of injury-mediated hyperalgesia [29]. These findings suggest that postoperative pain could partly result from inflammatory reactions.

In conclusion, this study demonstrated that midazolam co-administered with bupivacaine provided superior analgesic quality than did neostigmine by prolonging the duration of sensory and motor blockades and postoperative analgesia alongside reducing the need for postoperative pain relief. In addition, these beneficial effects were associated with hemodynamic stability. This might be explained by midazolam's better antioxidant and anti-inflammatory effects. Therefore, this drug could be considered an option for enhancing the effects of analgesics.

\section{Disclosure Statement}

The authors declare no conflicts of interest. The researchers are responsible for the content and writing of the paper.

\section{References}

1 El-Baradey GF, Elshmaa NS: The efficacy of adding dexamethasone, midazolam, or epinephrine to $0.5 \%$ bupivacaine in supraclavicular brachial plexus block. Saudi J Anaesth 2014;8:S78-83.

2 Kathuria S, Gupta S, Dhawan I: Dexmedetomidine as an adjuvant to ropivacaine in supraclavicular brachial plexus block. Saudi J Anaesth 2015; 9:148-154.

-3 Brattwall, M, Jildenstål P, Warrén SM, Jakobsson JG: Upper extremity nerve block: how can benefit, duration, and safety be improved? An update. F1000Res 2016;5.

4 Kwon Y, Hwang SM, Lee JJ, Kim JH: The effect of dexmedetomidine as an adjuvant to ropivacaine on the bispectral index for supraclavicular brachial plexus block. Korean J Anesthesiol 2015;68:32-36.

5 Naguib M, Sharif A, Seraj M, M. Gammal EL, Dawlatly AA: Ketamine for caudal analgesia in children: comparison with caudal bupivacaine. BJA: Br J Anaesth 1991; 67:559-564.

6 Erlacher W, Schuschnig C, Koinig H, Marhofer P, Melischek M, Mayer N, Kapral S: Clonidine as adjuvant for mepivacaine, ropivacaine and bupivacaine in axillary, perivascular brachial plexus block. Can J Anesth 2001;48:522-525.

7 Lauretti GR, Gomes JMA, Reis MP, Pereira NL: Low doses of epidural ketamine or neostigmine, but not midazolam, improve morphine analgesia in epidural terminal cancer pain therapy. J Clin Anesth 1999;11:663-668. 


\section{Cellular Physiology Cell Physiol Biochem 2018;46:2412-2420 and Biochemistry Published online: May 09, $2018 \quad \begin{aligned} & \text { DOI: 10.1159/000489647 } \\ & \begin{array}{l}\text { (c) } 2018 \text { The Author(s). Published by S. Karger AG, Basel } \\ \text { www.karger.com/cpb }\end{array}\end{aligned}$}

Sayyed et al.: Physiological and Biochemical Changes in Supraclavicular BPB

8 Francis C, Vitalis M, Thikra S: A randomised controlled trial comparing the effect of adjuvant intrathecal $2 \mathrm{mg}$ midazolam to 20 micrograms fentanyl on postoperative pain for patients undergoing lower limb orthopaedic surgery under spinal anaesthesia. Afri Health Sci 2016;16:282-291.

-9 Kohno T, Kumamoto E, Baba H, Ataka T, Okamoto M, Shimoji K, Yoshimura M: Actions of midazolam on GABAergic transmission in substantia gelatinosa neurons of adult rat spinal cord slices. Anesthesiology: Anesthesiologists 2000;92:507-507.

10 Yamamoto S, Yamada J, Ueno S, Kubota H, Furukawa T, Yamamoto S and Fukuda A: Insertion of $\alpha 7$ nicotinic receptors at neocortical layer V GABAergic synapses is induced by a benzodiazepine, midazolam. Cereb Cortex 2006;17:653-660.

11 Lin X, Wang Q Huang W, Yang B: Study on the mechanism of antinociception of intrathecal neostigmine in the formalin test in rats. Sichuan da xue xue bao. Yi xue ban 2003;34:698-700.

$\checkmark 12$ Yalçın AS, Kılınç A, Cöbek B: Evaluation of a simple colorimetric analysis for urinary malondialdehyde determination. Pathology and Laboratory Medicine International 2010;2009:23-26.

13 Vandesompele J, De Preter K, Pattyn F, Poppe B, Van Roy N, De Paepe A, Speleman F: Accurate normalization of real-time quantitative RT-PCR data by geometric averaging of multiple internal control genes. Genome biol 2002;3:research00341.

14 Laiq N, Khan MN, Arif M, Khan S: Midazolam with bupivacaine for improving analgesia quality in brachial plexus block for upper limb surgeries. J Coll Physicians Surg Pak 2008;18:674-678.

15 Kamali A, Shokrpour M, Vatanpour K, Eraghi MG: Midazolam versus neostigmineadding to lidocaine in post operation pain in colporrhaphy surgery in spinal anesthesia. Journal of Family and Reproductive Health 2012;6:2012.

16 Kumar P, Rudra A, Pan AK, Acharya A: Caudal additives in pediatrics: a comparison among midazolam, ketamine, and neostigmine coadministered with bupivacaine. Anesth Analg 2005;101:69-73.

$>17$ Li S, Yang Y, Yu C, Yao Y, Wu Y, Qian L, Cheung CW: Dexmedetomidine analgesia effects in patients undergoing dental implant surgery and its impact on postoperative inflammatory and oxidative stress. Oxid Med Cell Longev 2015;2015:186736.

18 Han C, Ding W, Jiang W, Chen YU, Hang D, Gu D, Jiang G, Tan Y, Ge Z, Ma T: A comparison of the effects of midazolam, propofol and dexmedetomidine on the antioxidant system: a randomized trial. Exp Ther Med 2015;9:2293-2298.

19 Kang MY, Tsuchiya M, Packer L, Manabe M: In vitro study on antioxidant potential of various drugs used in the perioperative period. Acta Anaesthesiol Scand 1998;42:4-12.

20 Thorburne SK, Juurlink BH: Low glutathione and high iron govern the susceptibility of oligodendroglial precursors to oxidative stress. J Neurochem 1996;67:1014-1022.

21 Li W, Wilker EH, Dorans KS, Rice MB, Schwartz J, Coull BA, Koutrakis P, Gold DR, Keaney JF, Lin H, Vasan RS, Benjamin EJ, Mittleman MA: Short-Term Exposure to Air Pollution and Biomarkers of Oxidative Stress: The Framingham Heart Study. Am Heart Assoc 2016;5:e002742.

-22 Bondok RS, Ahmed MA, Soliman NB, El-Shokry MH, Ali RM, Fahmy HF, Eldin MS: The effect of cholinesterase inhibition on liver dysfunction in experimental acute liver failure. Egyptian J Critical Care Medicine 2013;1:51-59.

-23 Kim HK, Kim JH, Gao X, Zhou JL, Lee I, Chung K, Chung JM: Analgesic effect of vitamin E is mediated by reducing central sensitization in neuropathic pain. Pain 2006;122:53-62.

-24 Eisenberg E, Shtahl S, Geller R, Reznick AZ, Sharf O, Ravbinovich M, Erenreich A, Nagler RM: Serum and salivary oxidative analysis in Complex Regional Pain Syndrome. Pain 2008;138:226-232.

25 Sayed S, Idriss NK, Sayyed HG, Ashry AA, Rafatt DM, Mohamed AO, Blann AD: Effects of propofol and isoflurane on haemodynamics and the inflammatory response in cardiopulmonary bypass surgery. Brit J Biomed Sci 2015;72:93-101.

26 Xu Z-Z, Zhang L, Liu T, Park JY, Berta T, Yang R, Serhan CN, Ji RR: Resolvins RvE1 and RvD1 attenuate inflammatory pain via central and peripheral actions. Nat Med 2010;16:592-597.

27 Zhang L, Berta T, Xu ZZ, Liu T, Park JY, Ji RR: TNF-alpha contributes to spinal cord synaptic plasticity and inflammatory pain: distinct role of TNF receptor subtypes 1 and 2. Pain 2011;152:419-427.

28 Dina OA, Green PG, Levine JD: Levine, Role of interleukin-6 in chronic muscle hyperalgesic priming. Neuroscience 2008;152:521-525.

29 Summer GJ, Romero-Sandoval EA, Bogen O, Dina OA, Khasar SG, Levine JD: Proinflammatory cytokines mediating burn-injury pain. Pain 2008;135:98-107. 